\title{
Teaching Translation of Poetry: A Collaborative Approach
}

\author{
Ahmad Mustafa Halimah ${ }^{1}$ \\ ${ }^{1}$ King Faisal University, AlAhsa, Kingdom of Saudi Arabia \\ Correspondence: Ahmad Mustafa Halimah, Associate Professor of Applied Linguistics and Translation Studies, \\ Department of English Language \& Literature, College of Arts, King Faisal University, AlAhsa, Kingdom of \\ Saudi Arabia. E-mail: ahalimah@kfu.edu.sa
}

\author{
Received: November 10, 2014 Accepted: December 17, 2014 Online Published: February 25, 2015 \\ doi:10.5539/ells.v5n1p26 URL: http://dx.doi.org/10.5539/ells.v5n1p26
}

\begin{abstract}
This study explores the application of a collaborative approach to the teaching of poetry translation as a literary genre to university Arabic speaking students. The collaborative approach is applied to the translation of Shakespeare's Sonnet XVIII "To His Love" into the Arabic Language. The participants in the experiment are two groups of female students and a Monolingual Arabic Language Specialist (MALS). Additionally, a set of ACNCS criteria were used to assess the quality of the translated texts. The discussion of the results and the qualitative analysis of the poetic extracts used in this paper indicated that the collaborative approach has resulted in improving the quality of students' translation, as the translated materials proved to be "novel and appropriate" as well as having validity from the MALS. Although this approach has some limitations, it can also be applied by teachers of other literary and none literary texts.
\end{abstract}

Keywords: poetry, translation, teaching, collaborative, ACNCS criteria, Monolingual Arabic Language Specialist (MALS)

\section{Introduction}

The concept of "collaboration" in teaching was initially used in an ESP setting where both the language and subject specialists work together in a classroom. Dudley-Evans and St John, (1998, p. 44), define collaboration in an ESP setting as "the direct working together of the language teacher and the subject teacher inside and/or outside the classroom in order that they prepare students to carry out particular tasks or courses". Together they plan and deliver the lesson in the classroom; while the subject teacher explains the subject matter and deals with problematic technicalities, the language teacher teaches the language that the subject matter is delivered through and addresses linguistically related matters. This form of collaboration is also called "team teaching".

Translation as a method for teaching and learning English can be traced back to the late nineteenth century when the grammar-translation method was very popular in classrooms. In this method lists of vocabulary were learned with their equivalents from the target language (Cook, 2003).

Collaboration in translation generally refers to the cooperation of translators, authors, publishers and translation agencies to produce a translation. In more specific terms it refers to the working together of two or more participants in order to produce a translation. This may of course happen in different settings, such as community and educational classroom settings (Pochhacker, 2004). The latter forms the focus of this paper.

Additionally, according to Andre Guyon (2010, p. 33), "collaborative translation is done by a group of individuals working together where coordination and discussions between participants are part and parcel of the translation process". In discussing the pros and cons of online collaborative translation, he also points out that "using today's web-based tools in collaborative translation could enable translators to share a text of unlimited length among unlimited number of translators and revisers" (Ibid).

Furthermore, in their article on "Supporting Multilingual Discussion for Collaborative translation", Ishida et al. (2012) propose an automated multilingual system for the collaborative translation of the multilingual discussions in different languages used for Wikipedia translation.

In her article on "Wanted: Best Practices for collaborative translation", Desilets (2011) discusses the effect of collaborative and social networking technologies on translation. She also mentions several uses of collaborative 
technologies in translation such as crowdsourcing, translation memory sharing, and online marketplaces for translators and others.

She also mentions the business gaols of an organisation as the main areas where translators, service providers and technologies vendors can use collaborative translation. To control the quality of the translation in such an environment, a crowd of professional translators can do that through a mechanism of voting, mutual revision and appropriate management.

An important element of successful collaborative translation activity is "the presence of a compelling incentive for member of the group or crowd to participate. Motivation issues are most critical in crowdsourcing scenarios". (ibid, p. 4).

The role of the professional subject-matter teacher and the language teacher should be played well in collaborative translation to ensure professional level quality of the translated text. They can achieve this by revising and vetting the final product.

About the approaches used in teaching translation to Arabic speaking University students, Al-Shabab (1998, p. 2) tended to classify them into three types: (1) the ready-made translated text model, (2) the grammatical structure model and (3) the dynamic on-going process model. As an alternative to these approaches and based on Hermeneutic approaches to translation studies (Herman, 2011), Al-shabab (ibid, p. 3) suggests a Textual Manipulation approach of three aspects of teaching translation in general: "Textual Manipulation, creating context; Textual manipulation, paraphrasing, and Textual manipulation: addition and omission of information. He did not seem to refer to collaboration as a potential translation teaching method which could be used in a classroom with Arabic speaking students.

When it comes to the issue of evaluation of translated texts, (Bassnett, 1980/2014, p. 21), points out that "There is no universal canon according to which texts may be assessed. There are whole sets of canons that shift and change and each text is involved in a continuing dialectical relationship with other sets."

With regard to the criteria governing the translation of poetry, Susan Bassnett, in her book on Translation Studies (1980), gives a brief survey, extending from a structural approach where the linguistic and formal structures of the original poem form the basis of the criteria used by the translator, the seven different strategies suggested by Andre Lefevere (1975) such as Phonemic translation, literal translation, metrical translation, poetry into prose, rhymed translation, blank verse translation and interpretation, criteria of length, shape, organisation of lines and tone of poetry translation, discoursal translation giving priority to conversational tone and mood to principles of interpretation and accuracy of translation.

Moreover, for evaluating literary translations in general and poetry in particular, terms like "accuracy" (Bassnett, 1980, p. 180) "clearness", (Fadaee, 2011, p. 200), "naturalness" (Newmark, 1988, p. 75) and "communicative purpose" (Nord, 2006, p. 44) have been used as criteria that would guide translators in their processing and producing the translated poem.

However, there are certain constraints we need to take into account when translating any literary text so that we don't lose sight of the main purpose of our translation. Moreover, our translated text (TT) would not read strange and irrelevant. These constraints can be expressed in terms of criteria or a checklist we could always refer to while we are engaged in the process and product of the translation. In order of importance, they are listed in Appendix A below.

Thus as a creative translator engaged in translating a literary text, you need to be aware of the fact that creative translation tends to be less rigid in its adherence to the theoretical procedures normally followed in translation in general as this would enable you to use the mechanism that operates the translating process of literary text-types more effectively as in the translation of poetry, drama, short stories and others.

A suitable approach to looking into the teaching of poetry translation to Arabic Speaking students is a collaborative approach as this would give the students the freedom to work at their own pace with less apprehension of being criticised by the teacher. This approach would give us as teachers of translation the ability to compare how student translators use their collaborative skills and exegetical tools for understanding, interpreting and applying the ACNCS criteria to their task of translation.

Having made those references and being a practitioner interested in the translation product of poetry, I am tempted to adopt a product collaborative approach to translation loaded with constraints of the cultural and stylistics norms of poetry carried in the text. In other words, any collaborative translation of the meanings of the poetry is accepted if it does not violate any of the principal cultural and stylistic criteria of poetry translation and it is rejected if it does. To achieve such an acceptable version of poetry in Arabic, the translated text should 
achieve maximum approximation in equivalence and the communicative purpose of the text should be conveyed in an appropriate style without violating any cultural and poetic features of the poem to be translated. A translation of this standard should obviously endeavour to transfer into Arabic the linguistic, social, cultural and stylistic associations and connotations of the original text, in addition to its rhythmic and rhyming impact on the TL reader or receptor, if possible.

However, there is no one specific method or approach or even strategy one can exclusively use in translating literary texts as this depends on several elements involved in the translation of a literary text such as the nature and purpose of the Source Text, the translator as a reader and translator of the ST, the readers of translated texts and nature of TL among other essential elements.

As a working definition, "creative translation" is used here to refer to the process of transferring a literary text in one language with utmost accuracy, clarity, naturalness, communicative effects and stylistic features of the source text into a target literary text in another language (henceforth ACNCS criteria). Achieving such a challenging task falls on the shoulders of the creative translator who needs to look at the aforementioned ACNCS criteria as the main principles that would guide him/her to process and produce a translated literary text that is imaginatively novel, stylistically right and beautifully appropriate.

\subsection{Research Question}

The following question was formed to investigate the impact of using a collaborative approach on the quality of students' translation of English poetry.

Does a collaborative approach to teaching of translation improve the quality of University Arabic Speaking students' translation of English Poetry?

\section{Methodology}

The aim of this study was to investigate the effectiveness of "collaboration" as a teaching method to help students improve the quality of their translation of English poetry into Arabic.

To achieve this aim, a group of 9 female students and a monolingual Arabic language specialist collaborated in translating Shakespeare's "To His Love" into Arabic subsequent to structured team-teaching by the author and an MALS. Students' translated texts were then evaluated according to a five-point scale. Since the data is in two languages, a bilingual and bicultural teacher as well as an MALS evaluated the translated texts using the set of the ACNCS criteria.

Throughout this study it has been assumed that the subjects use Arabic in their everyday conversation and written communication and that they are comparatively capable users of Standard Arabic (SA). Nevertheless, the languages of instruction in the classroom were English and Arabic.

\subsection{Participants}

An aggregate of 9 female undergraduate students majoring in English Language and Literature at King Faisal University formed the participants for this study.They were divided into three groups of three participants. Arabic is the native language of all those participants and their goal was to translate given texts from English into Arabic. These were students of the seventh academic semester and had already passed all prerequisites to Creative Translation Course No.472 Level 7, which is one term long, a two-hour session per week for 15 weeks, the size of the group is between 9-15 students and the resources were prepared by the author who designed and taught the course for three years. Overall, they all had the same level of theoretical and practical foundations, principles and guidelines of translation.

\subsection{Evaluators}

The author, a bilingual and bicultural in both British English and Arabic, and a monolingual Arabic Language Specialist - the so-called Arabic poet- participated, collaborated, team-taught and assessed the participants' translated texts inside and outside the classroom, applying the same grading criteria of ACNCS.

\subsection{Treatment of the Experimental Group}

Students in the experimental group received collaborative instruction using extracts of poetry as the main part of their creative translation course over a period of 5 weeks out of a 15 -week long course. This course was ranked as level seven out of 8 levels to be mastered as a prerequisite for graduating. The major aim of the course was to move them away from using a literal translation approach and taking them towards developing a creative approach to translating literary texts such as poetry. At other parts of the course, students translated literary 
works in class such as short stories, drama, orations as main literary genres. The creative translation lectures were each two-hours long.

Students were asked to take into account the following criteria while translating a literary text such as poetry. (See appendix A for more details about these criteria).

1) Accuracy, which refers to the ability to faithfully convey the exact and precise meanings of the source text to the target text.

2) Clarity in translation refers to intelligibility without causing the translated text reader to exert any extra mental effort to understand what is meant by the content of the TT.

3) Naturalness in translation refers to the ability of the creative translator to apply appropriate natural forms and norms of the Target Language to the source text, which he/she is translating, be these forms and norms linguistic, sociolinguistic, psychological, sociocultural, and communicative or others.

4) Communication, which in poetry translation pertains to the ability of the translator to transfer not only the meaning but also the emotional aspects of the ST to the target reader as effectively and faithfully as they are communicated to the ST readers in the first place.

5) Style in literary texts refers to the linguistic devices the author uses in his/her writing to tell a narrative, to describe events, objects and characters or to voice out his/her ideas and views in a manner of their choosing, be it formal, informal, casual or archaic. It refers to the ability to transfer the stylistic features of the ST to the target text with the same stylistic force used by the ST writer or speaker.

Due to the limited time, space and scope of this paper, samples of only one group of three students will be randomly selected, discussed and analysed.

\subsection{Treatment of Control Group}

Students in the control group received instruction normally used in translation classes at Arab Universities in general and Saudi Universities in particular, where neither cooperation nor collaboration with Arabic Language specialists would be sought. Instead, the teacher would choose the literary text -a poem in our case- ask students to translate it at home and bring it to class for discussion and feedback. The teacher would be the main authority in the classroom.

\subsection{Material}

Upon the completion of the five weeks of provision of poetry transactions to the participants and after reviewing and considering a number of English short poems, a well-known poem was selected and given to participants in order to translate it from English to Arabic. The poem was Shakespeare's Sonnet XVIII "To his love". This poem was chosen because it was relatively new to the students, it relates to the field of English Literature, is very popular among students majoring in English Language and Literature, contains a descriptive and expressive nature, and is more challenging and more revealing of the set of the ACNCS criteria in the participants' performance in translation.

The poem was read; its difficult terms were explained and discussed in the class. Many discussions on different linguistic, stylistic and cultural aspects of the poem were debated and personal interpretations of the poem were shared with all participants. Doing this with the whole of the class and sharing views with them was significant to the researcher as this would minimise the difficulties that the participants would encounter and help them be better prepared in terms of accurate understanding and interpretation of the mood and spirit of the poem, which consequently will enable them to reproduce an Arabic recreation of the feelings and emotions embedded in the poem.

\subsection{Procedure}

The Participants, in both groups, were asked to do the translation as a one-week home assignment with a sufficient amount of time to spend on the task and away from any classroom inhibitions. The experimental group participants, however, worked together in groups of threes whereas the other control group participants worked individually on their own.

In the week after, control group participants translated the poem at home and brought it to the class for discussion and feedback. The teacher was the main authority in the classroom, whereas the experimental group participants brought their translated version of the poem to the class where in-depth understanding and interpretation of the source text were achieved through discussion and negotiations between the teacher, MALS and the student participants. 
The sample collaborative group of three informed the researcher that their collaboration involved not only initial understanding, interpretation and discussion of the Source Text, but also alternation of the Translated Text among themselves. In other words, student $\mathrm{A}$ in the group produced the first draft while the other two brainstormed to improve it. Then student B took up the draft produced by student A and spent some time working on improving it and trying to approximate it as much as possible to the original text. Student $\mathrm{C}$, then, took up the second draft to put her final creative touches on the translated text. After this laborious collaborative work, they met again to agree on the final copy of the translated text. This final copy was given to the Arabic Language Specialist to evaluate and then in collaboration with the participants and the teacher put his poetic touches on it giving it a higher level of creative translation of poetry by turning it into an Arabic Shakespearean Sonnet!

Although it may sound quite time consuming and laborious, it is worthwhile in terms of the quality of the translated text on the one hand and in terms of students' learning, motivation, self-esteem development and teamwork enhancement

\section{Results and Discussion}

How to translate poetry is a very complicated process; some would say "dismantle the original poem and build" the translation and others would say "make a close reading and writing of the source text" and then be creative and inventive in your translation (Boase-Beier, 2011, p. 196). David Pendlebury (2005, p. 15) suggests A Two-Stage Approach: where the translator "produces a draft translation of the original that is as literal and accurate as possible". Then he translates "this draft, with only minimal reference to the original". He calls this stage a "weaning away" from the original stage. However, there seems to be several different ways of translating poetry but it would be fair to say that most poetry translators aim to create a translation that works as poetry in the target language and has the same equivalent-effect on the translated text reader.

In translating our sample poem below "To His Love" taken from Shakespeare's Sonnets and other poetry (1609/2004, Sonnet XVIII, p. 15), a collaborative approach with the ACNCS criteria have been used as a governing body of rules and guidelines for participating students to use. In other words, the randomly selected collaborative group of three students, the present author and a Monolingual Arabic Language Specialist have worked together to process and produce four versions of the translation of this English poem. During the process of their four translations there was a continuous consultation among the students on the one hand; and the students, the present author and MLAS on the other hand, starting with Version (A) as a literal translation, then rewriting it in Version (B), improving on it in version (C) and then producing it as a "poem to poem" translation in version (D). (For more analysis, see below).

\section{"To His Love"}

Shall I compare thee to a summer's day?

Thou art more lovely and more temperate:

Rough winds do shake the darling buds of May,

And summer's lease hath all too short a date;

Sometime too hot the eye of heaven shines,

And often is his gold complexion dimm'd;

And every fair from fair sometime declines,

By chance or nature's changing course untrimm'd;

But thy eternal summer shall not fade,

Nor lose possession of that fair thou ow'st;

Nor shall death brag thou wander'st in his shade,

When in eternal lines to time thou grow'st:

So long as men can breathe or eyes can see,

So long lives this, and this gives life to thee. 


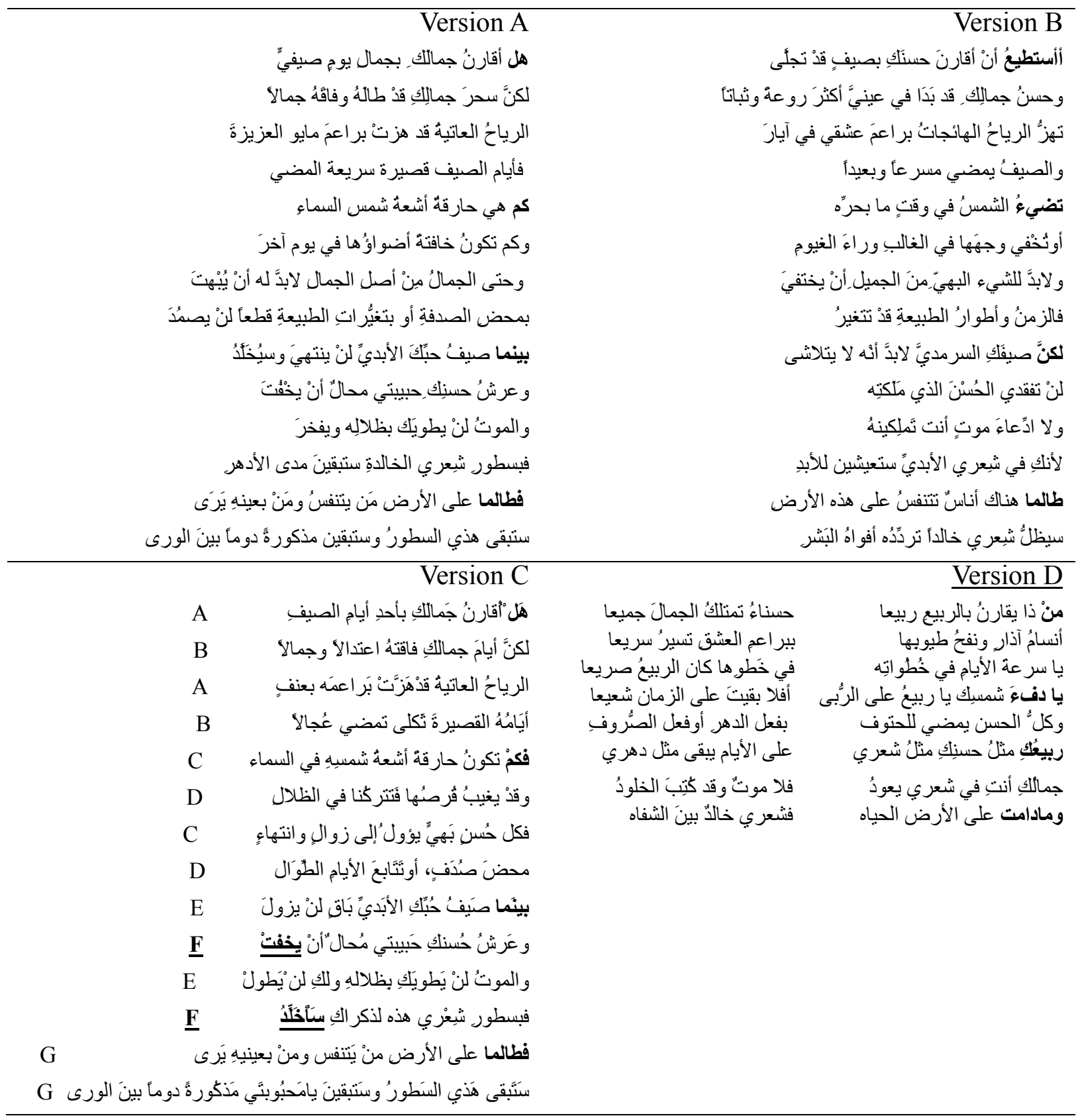

Collaboration among students in translating the SL poem is evident as the quality of the Target Text poem seems to improve gradually. The higher the intensity of collaboration and the application of the ACNCS governing criteria is, the better the Target Text gets until it achieves the highest level of approximation to the original poem in terms of accuracy, clarity, naturalness, communicative purpose and style. The rest of the discussion will focus on the TT versions individually and see whether collaboration was useful and how much of the ACNCS criteria have been successfully met.

As a starting point, the translators of the above English poem tried not only to understand its denotative meanings and connotative associations but also to interpret it in terms of its shape, form, context, purpose and style. With regard to the shape and form of the poem, it is normally divided into a three four-line stanzas and a concluding two- line-couplet. The line is defined in terms of feet. A foot is a conventional group of stressed and/or unstressed syllables in a particular order (Dickens et al., 2001, p. 89).

In terms of context, the SL poem reflects a period remote in time where Shakespeare as a poet is dead and the significance of the context of the poem seems to be dead as well. When it comes to rendering it to a TL context, 
it requires from the translators a creative ability to recreate a TT context that is equivalent to that of the original one in terms of the communicative purpose and style of the original poem.

In terms of style, the main purpose of the SL poem is not only to describe the beauty of the poet's beloved in a high register style but also to eternalise her beauty through his magnificent poetry and make it as a guide for lovers to follow. Now we need to ask the following question: Have the translators of the versions below managed to achieve a high register style similar to that of Shakespeare?

\section{Version A}

This translation retains the overall division of the original poem into four-line stanzas and a two-line concluding couplet. The number of words it uses is 98 Arabic words versus 114 English words used in the ST poem. All this seems to be an attempt to approximate the shape and size of the TT to that of the ST. However, is it appropriate to use this shape in classical Arabic poetry? Or is it more practical to use it because it looks like some of our Arabic contemporary poetry? A decision needs to be made between appropriateness and practicality. My choice in creative translation would be "appropriateness" because it makes your TT sound more communicatively effective and stylistically acceptable in the TL context.

The translation is not rhyme-based but rather it is written in poor prose. Their use of the word "azizah" for the word "darling" at the end of line three is not only inaccurate but also inappropriate as it is used to denote a quality of man that is "dignity" and "rarity", both meanings seem to be irrelevant. The words in line eight " بحصض "الصدفة أو تغيرات الطبيعة "belong to low register (i.e., colloquial) and are awkwardly intertwined which is not appropriate for use in this context.

The translation seems to be quite literal as it concerns itself with the denotative meanings of the words only, overlooking the connotative associations and stylistic features of the ST. Repeating the word "jamal/beauty" four times in the first pair of lines, for example, violates the integrity of the sonnet, as linguistic concision in poetry is of a paramount importance, where every foot and syllable counts. The degree of repetition in translating this great poem not only distorts the image of the beloved portrayed in the poem but also reduces the meaning of "beauty" implied in the words of "more lovely and more temperate" because it implies that the summer is lovelier than her beauty, which isn't what Shakespeare intended to convey. The tone sounds tautological, uneasy and uninteresting.

Moreover, translating the word "summer" into "assaif/summer" is not appropriate as the connotations of "assaif" in Arabic tend be unlike those in English and carry rather negative connotations as in harsh weather conditions, draught and limited outdoor mobility. Hence, the use of "assaif" deprives the TT poem of the loving and compassionate tone felt in the original ST poem. Contrastively, the season used in Arabic to refer to the beauty of the beloved is not "assaif الربيع but rather "arrabee" which carries connotations of beauty and liveliness.

A comparison between the connotations of the English and Arabic summers will show the seriousness of the problem that the translator may face while working on something relating to climatic features:

English Summer

- A Symbol of beauty \& liveliness

- Very short 1-2 months

- Cool and temperate

- Positive psychological effect
Arabic Summer

- $\quad$ Very long 3-4 months

- Dry/humid and hot

- Negative psychological effect

The above rough comparison shows that if English summer is translated in Arabic "summer/صيف", the translation won't make any sense to the Arabic reader, because his/her attitude towards summer is different from that of the English reader. Therefore, the "substitution" approach could be used to solve a problem as such. The substitution approach is one of a number of concepts and techniques in the general class of ordered metamorphosis. Substitution can operate in a way that maintains the matter and logic of a theme while altering the expression convention (Steiner, 1975). In other words, Version A translators above could have substituted the Arabic Spring "الربيع" for the English summer as the connotations of Arabic Spring are more or less the same as those of the English summer. A rough comparison may illustrate this point: 
English Summer

- A Symbol of beauty \& liveliness

- Very short 1-2 months

- Cool and temperate

- Positive psychological effect
Arabic Spring

- A Symbol of beauty \& liveliness

- Very short 1-2 months

- Cool and temperate

- Positive psychological effect

An alternative translation of the above four-line stanza could be seen in Version D above.

In general, the translators seem to have opted for a word-for-word orientation to the task of translating this poem in stage one. They have tried to find the exact equivalent of each word, which resulted in producing an odd-sounding TL version that is far away from owning poetical rhythm and has misrepresented the author's intentions. Lack of accuracy, clarity and naturalness in the above translation has made the poem drag on because of its elaborate and unnecessary long sentences. Additionally, the toneless voice has in turn changed the translation and made it ineffective communicatively let alone poetically effective. It seems to have failed the ACNCS criteria.

\section{Version B}

This translation sounds and reads slightly better than Version A because it has been modified and improved in terms of the linguistic structures and the stylistic choices made by the translators in consultation with the researcher and the MLAS. It, however, still retains the overall division of the original poem into four-line stanzas and a two-line concluding couplet. The number of words used in the poem is 92 , which make it a less amount than the number of words used in version A. This translation like that of version A does not seem to be rhyme-based either but rather a prose-based structure. All these features tend to still stand short of achieving the ACNCS criteria aimed for.

To illustrate, if we look at line one which starts with the verb "أستطيح = can I", for example, we can immediately as Arabic speakers realise that it is a non-poetic expression to start a poem with, unlike that of Shakespeare's, as it is prosaic and of a low register vocabulary in Arabic. A better expression would be "هل يمكني = would I be able to" as it sounds more poetic and of high register which would be more compatible with Shakespeare's words "Shall I". Moreover, although Arabic prefers a verb-subject structure, the verb-subject structure used in line 3 "تهز الرياح الهائجات بر اعم عشقي" read smoothly or flow comfortably. To maintain Shakespeare's view of his beloved's beauty as better than that of the summer's day, he confirms that her beauty is for all times not only in the summer. If the translators added the " $"$ " as indicated below and translated it as follows, they would have achieved what Shakespeare wanted to achieve.

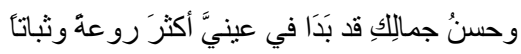

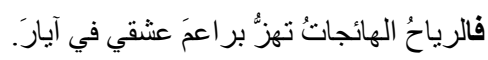

\section{Version C}

Unlike versions $\mathrm{A}$ and $\mathrm{B}$, version $\mathrm{C}$ seems to have achieved some kind of positive approximation to the ST although it has 98 words, which is more than the number of words used in each of A and B. Taking the first and second stanzas, for example, the translators seem to have achieved a rhythm Translated Text benefiting from the assonance applied to the end of line 1 with " لصيف", and they continue doing this with some kind of success until

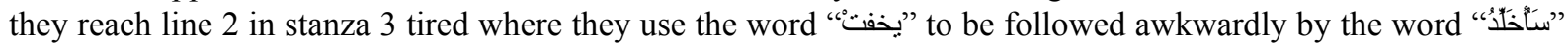
in line 3. Those two words don't rhyme well and violate the norm of finishing the poem with a good rhythmic sound. Furthermore, some of the structures were poorly used as it can be seen in " stanza 2 line 4 and the use of "ف" "بطور" "with a noun stanza 3 line 4.

Retaining the overall division of the original poem into four-line stanzas and a two-line concluding couplet seems to be acceptable in version $\mathrm{C}$ as far as rhyming is concerned, because it does not cause any noticeable inconvenience while reading it in Arabic. It also seems to leave some kind of emotive effect on the TL reader.

In general and in terms of the ACNCS criteria, this translation is acceptable because it has a poetic feel, a rhythmic finish to the words, and clarity in the emotional effect it achieves on the TL reader. 


\section{Version D}

It is obvious that the three Arabic versions A, B and C of the English poem above are very different from Version $\mathrm{D}$ in terms of length, shape, organisation of lines and they are enormously different in tone.

The version D translation has been classically organised in as short as eight lines and 78 words only, which is an indicator of linguistic conciseness and preciseness. The lines are divided into two hemistichs (شطر), the first half of the line is called الثنطر الأول and the second half is called الثطر الثاني, these are separated by a little gap in the text. This feature complies with the classical standard of Arabic poetry.

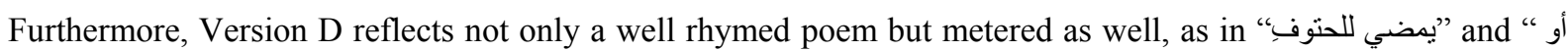

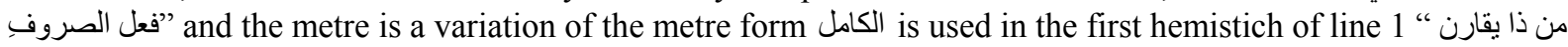

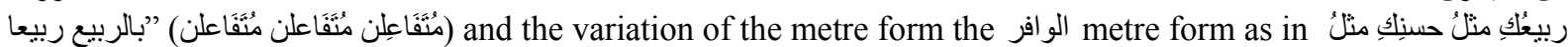
in the first hemistich of line 6. This variation in the metre maintains the rhythm and melody required to please the TL reader or listener.

What is striking about this translation is the cultural dimension that the MALS managed to achieve in the final stage of collaboration with the students and the researcher by not only substituting the word " الصيف = summer" by the word "الربيع spring" but also by achieving a poetic tone that is loving, admiring, breezy, joyful, melancholic, romantic and everlasting.

Moreover, the linguistic choices, be they lexical, structural or stylistic, tend to be of a high register which make it the most approximate translation of the ST poem. The ACNCS criteria are nicely met in version D.

In this translation, in which the translators with the collaboration of MALS adopted a thought-for-thought approach, the Arabic version sounds more fluent, transparent, communicative and natural. This version reveals not what Shakespeare wrote about his beloved but rather what he meant to say to his beloved and about her everlasting beauty, which is clearly emotionally felt by the TL reader and is psychologically effective and poetically appreciated.

According Bassnett (1980:66), translation of poetry tends to "show faithfulness not to individual words or sentence structures but to a notion of the meaning of the poem in its relationship to its readers. In other words, the poem is perceived as an artefact of a particular cultural system, and the only faithful translation can be to give it a similar function in the target cultural system". The version D translation above is a good example.

\section{Conclusion}

This study showed how the collaborative approach resulted in improving the quality of students' translation. The results drawn from the experiment show that the translated materials in Versions A, B, C and D were graded in order of "novelty and appropriateness" in compliance with the ACNCS criteria used in this study and also received approval from the Monolingual Arabic Language Specialist's point of view.

Although this approach has some limitations, particularly with regard to the availability of a monolingual Arabic language poets for creative translation classes, teachers and students can still seek collaboration from Arabic Language Specialists in the Department of Arabic Language Studies at the University.

It is hoped that this approach can also be explored and used by those who are interested in not only the translation of Arabic/English poetry and other literary genres, but also other text types, such as technical/scientific, business, legal or even medical texts that will obviously require a medical language specialist.

\section{References}

Al-Shabab, O. S. (1998). Translating with difference: Theory and Practice. DEBS, Damascus, Syria.

Cook, G. (2003). Applied Linguistics. Oxford University Press

Desilets, A. (2011). Wanted: Best Practices for Collaborative Translation, TAUS 2011. Retrieved from http://www.translationautomaion.com

Fadaee, E. (2011). Translation naturalness in literary works: English to Persian. Internal Journal of English and Literature, 2(9), 200-205.

Guyon, A. (2010). The Ups and Downs of Online Collaborative Translation. TERMIUM Plus, Public Works and Government Services Canada 2014.

Ishida, N., Lin, D., Takasaki, T., \& Ishida, T. (2012). Supporting Multilingual Discussion for Collaborative Translation. IEEE, Department of Social Informatics, Kyoto University, Japan. 
Newmark, P. (1988). A Textbook of Translation. Prentice Hall International (UK) Ltd.

Nide, E. A. (2001). Language, Culture and Translating. Shanghai Foreign Language Education Press.

Nord, C. (2006). Translating for Communicative Purposes across Culture Boundaries. Journal of Translation Studies, 9(1), 43-60.

Pendlebury, D. (2005). “Creative Translation” Monograph Series No. 48, the Insitute of Cultural Research, Antony Row Ltd. Eastbourne, UK.

Perteghella, M., \& Loffedo, E. (2006). Translation and Creativity. New York and London: Continuum International Publishing.

Shakespeare, W. (2004). Sonnets and other Poetry. Great Reads, Planet Three Publishing Network Ltd., Germany.

\section{Appendix A}

\section{The Five Criteria Model for evaluating translation of poetry}

The following checklist is given to the student translators to refer to while they are engaged in the process and product of the translation.

The students' collaborative translations are to be graded on five-point scale areas. This represents the range of approximate equivalence with the highest degree of "adequacy and validity" from being a poor translation to being a highly skilled poetry translation. In order of importance, they are as follows:

1. Accuracy is the most important criterion to assess the quality of a translated text. To be accurate is to represent something in accordance with the way it actually is. It refers to the conveyance of the exact and precise meanings of the source text to the target text. To be certain about achieving "accuracy" in translation, the following questions could be asked: Has the translator been faithful in rendering the exact meanings of the ST to the TT? Has any information mentioned in the ST been missed or omitted? Has any new information been added to the TT? Is there any shade of meaning missing? Has the overall meaning of the ST been transferred successfully to the TT? etc.

2. Clarity in translation is an integral part of the comprehension process of the TT reader. To be clear is to be intelligible without causing the TT reader to exert extra mental effort to understand the content of the TT. In other words, clarity in translation means that the reader can understand the text without any difficulty or having the need to refer to any off-site explanation whether inside the text or in a form of footnote. To be certain about achieving "clarity" in your translation, the following questions could be asked: Is the TT easy to understand? Does it require from the target reader any extra exerted effort to comprehend it? Does it read smoothly and comfortably? Has the ST Message been communicated clearly to the reader of the TT? etc.

3. Naturalness in translation refers to the ability of the creative translator to apply appropriate natural forms and norms of the Target Language to the source text, which he /she is translating; be these forms and norms linguistic, sociolinguistic, psychological, sociocultural, communicative or other. To achieve naturalness in your translation the following questions should be asked: Does the TT sound and read like an authentic English text? Does it have the dynamicness and idiomaticness normally used in an authentic English text? Does it have the "natural wow factor?" etc.

4. Communication in translation in general and in creative translation particularly involves transferring not only the meaning but also the emotional aspects of the ST to the TT readers as effectively and faithfully as they are communicated to the ST readers in the first place. In other words, a creative translator has to ensure that they understand the communicative purpose of the ST and endeavour to achieve it in the TT, be it poetry, novels, short stories, drama, oratory or any other type of literary text. The following questions should be asked to check for this criterion: What is the main communicative purpose of the ST? For example, is it to persuade, to entertain, to delight, to instruct or to inform? Does the TT carry the same meaning and emotional force of the ST?

5. Style in literary texts refers to the linguistic choices the author makes in his/her writing to tell a narrative, to describe events, objects and characters or to voice out his/her ideas and views in a manner of his /her choosing, be it formal, informal, casual or archaic. The author's style in literary texts tends to influence how we interpret the facts and information. Therefore, a creative translator needs to be aware of these features and be able to transfer the stylistic features of the ST to the TT with the same stylistic force used by the ST writer or speaker. In other words, you need to identify the historical, geographical, and cultural dimensions of the style used in ST and endeavour to apply it to the TT with utmost accuracy, clarity, naturalness and communicative force. 


\section{Copyrights}

Copyright for this article is retained by the author(s), with first publication rights granted to the journal.

This is an open-access article distributed under the terms and conditions of the Creative Commons Attribution license (http://creativecommons.org/licenses/by/3.0/). 